\title{
Temperature shapes movement and habitat selection by a heat-
}

\section{sensitive ungulate}

6 Jesse M. Alston, Program in Ecology and Department of Zoology and Physiology, University of

10 Jerod A. Merkle, Department of Zoology and Physiology, University of Wyoming, Laramie,

12 Ron A. Moen, Department of Biology and Natural Resources Research Institute, University of 


\section{Abstract}

\section{Context}

20 Warmer weather caused by climate change poses increasingly serious threats to the persistence

21 of many species, but animals can modify behavior to mitigate at least some of the threats posed

22 by warmer temperatures. Identifying and characterizing how animals modify behavior to avoid

23 the negative consequences of acute heat will be crucial for understanding how animals will

24 respond to warmer temperatures in the future.

\section{Objectives}

27 We studied the extent to which moose (Alces alces), a species known to be sensitive to heat,

28 mitigates heat on hot summer days via multiple different behaviors: (1) reduced movement, (2)

29 increased visitation to shade, (3) increased visitation to water, or (4) a combination of these

30 behaviors.

\section{Methods}

33 We used GPS telemetry and a step-selection function to analyze movement and habitat selection

34 by moose in northeastern Minnesota, USA.

\section{Results}

37 Moose reduced movement, used areas of the landscape with more shade, and traveled nearer to

38 mixed forests and bogs during periods of heat. Moose used shade far more than water to

39 ameliorate heat, and the most pronounced changes in behavior occurred between $15^{\circ} \mathrm{C}$ and $20^{\circ} \mathrm{C}$. 


\section{Conclusions}

42 Research characterizing the behaviors animals use to facilitate thermoregulation will aid

43 conservation of heat-sensitive species in a warming world. The modeling framework presented

44 in this study is a promising method for evaluating the influence of temperature on movement and

45 habitat selection.

46

$47 \quad$ Key words

48 climate change, habitat selection, habitat use, lidar, moose (Alces alces), resource selection, step-

49 selection function, thermal refugia

50

51 


\section{Introduction}

Physiological performance peaks within a limited range of body temperatures in which

54 molecular, cellular, and systemic processes operate optimally. Body temperatures outside this

55 range impose functional constraints on these processes, including reductions in growth,

56 reproduction, activity, and immune function (Pörtner and Farrell 2008). Nevertheless, animals

57 routinely operate in environmental conditions that trigger suboptimal body temperatures (Boyles

58 et al. 2011; Sunday et al. 2014). This conundrum underlies two long-standing questions in

59 biological research: (1) How do animals mitigate suboptimal thermal conditions, and (2) how

60 effective are those efforts at mitigation? Rapid and ongoing responses to global climate change

61 by a multitude of animal species (Walther et al. 2002; Parmesan 2006; Hoegh-Guldberg and

62 Bruno 2010) increase the urgency of answering these questions.

63 Animals can relax the constraints of limited ranges of thermal tolerance by modifying

64 their behavior to reduce heat gain and dissipate heat at high temperatures. Such behavioral

65 thermoregulation has a long history of study in biological research (Cowles and Bogert 1944),

66 but this idea still offers fresh insight today. Animals can restrict movement to produce less

67 metabolic heat (Stelzner 1988; Broders et al. 2012), alter posture to reduce heat gain from

68 insolation or increase surface area to shed heat (Luskick et al. 1978; Bartholomew and Dawson

69 1979), pant to lose heat via evaporation (Campos and Fedigan 2009; McCann et al. 2013), or

70 visit thermal refugia (spaces that provide refuge from thermal stress caused by extreme

71 temperatures [e.g., burrows, wallows, shade cover]; van Beest et al. 2012; Hovick et al. 2014;

72 Kurylyk et al. 2015), among other behaviors. Identifying exactly which of these strategies

73 animals use to behaviorally thermoregulate, how much these strategies buffer against adverse

74 impacts of hot weather, and what costs animals incur to use these strategies is crucial for 
75 understanding their ability to increase ranges of thermal tolerance, which in turn increases our

76 understanding of how animals may adapt (or not) to increasing temperatures in a warmer future.

77 Recent advances in statistical modeling techniques provide opportunity to study

78 behavioral thermoregulation in new ways. Step-selection functions (hereafter "SSFs") are an

79 extension of the resource selection function modeling framework that explicitly incorporates

80 spatial and temporal animal movement characteristics to enable examination of fine-scale habitat

81 selection and movement behavior at biologically realistic scales (Forester et al. 2009; Thurfjell et

82 al. 2014; Duchesne et al. 2015; Signer et al. 2019). SSFs have primarily been used to model

83 habitat selection (Thurfjell et al. 2014), but recent theoretical development has demonstrated that

84 they can also be used to explicitly model movement behavior that changes in both space and time

85 in relation to landscape features (Avgar et al. 2016; Prokopenko et al. 2017; Ladle et al. 2019;

86 Signer et al. 2019). By including interaction terms between temperature, habitat covariates, and

87 movement rates within SSFs, the relative importance of temperature-dependent animal

88 behaviors - including both resource selection and movement rates - can be quantified in a single

89 model.

90 We used the SSF modeling framework to examine behavioral thermoregulation in moose

91 (Alces alces), a species known to be sensitive to heat. Moose have undergone substantial

92 population declines across much of their southern range due in part to climate change (Lenarz et

93 al. 2010; van Beest et al. 2012; Dou et al. 2013; Monteith et al. 2015). Moose experience heat

94 stress starting at temperatures as low as $14^{\circ} \mathrm{C}$ (Renecker and Hudson 1986) or $17^{\circ} \mathrm{C}(\mathrm{McCann}$ et

95 al. 2013) during the summer. Moose prevent heat stress on hot days by using water, shade, and

96 decreased activity to shed heat via conduction and reduced exposure to radiation from the sun

97 (Fig. 1; Belovsky 1981; Dussault et al. 2004; Broders et al. 2012; Street et al. 2015; McCann et 
98 al. 2016). At coarse spatial and temporal scales, moose select for thermal cover (e.g., dense

99 canopy in conifer forests) during periods of high temperatures (Schwab and Pitt 1991; Demarchi

100 and Bunnell 1995; van Beest et al. 2012; Melin et al. 2014; Street et al. 2016; but see Lowe et al.

101 2010). However, earlier studies have not established the relative importance of multiple different

102 heat amelioration strategies (e.g., seeking shade vs. reducing movement vs. visiting water) or

103 identified thresholds at which behavioral thermoregulation alters habitat selection.

104 To evaluate how moose modify fine-scale habitat selection and movement patterns as

105 temperatures increase, we used an SSF to assess the effects of temperature on movement and

106 resource selection. We examined empirical support for a single model consisting of temperature

107 and interactions with variables likely to be important for moose thermoregulation. This model

108 enabled us to quantify the importance of several ways moose may alter behavior to

109 thermoregulate when it is hot: moose (1) decrease movement rates to decrease metabolic heat

110 production, (2) increase use of shade to decrease heat gain from solar radiation, (3) increase use

111 of water to increase heat loss via conduction, convection, and evaporation, or (4) use some

112 combination of each of these.

\section{Materials and Methods}

\section{Study area}

116 We conducted our study in northeastern Minnesota, USA. Federal, state, county, and

117 tribal public lands managed for timber harvest and recreation make up $>80 \%$ of property

118 ownership in the area. The region is a sub-boreal transition zone between northern hardwood

119 forests in the south and Canadian boreal forests in the north (Pastor and Mladenoff 1992).

120 Upland forests are primarily composed of white, red, and jack pine (Pinus strobus, P. resinosa, 
121 and P. banksiana), aspen (Populus tremuloides), paper birch (Betula papyrifera), and balsam fir

122 (Abies balsamea). Black spruce (Picea mariana), tamarack (Larix laricina), and northern white

123 cedar (Thuja occidentalis) dominate wet lowland forests. Mean minimum and maximum

124 temperatures, respectively, are $-16.5^{\circ} \mathrm{C}$ and $-5.5^{\circ} \mathrm{C}$ for the month of January and $12.6^{\circ} \mathrm{C}$ and

$12524.0^{\circ} \mathrm{C}$ for the month of July at the Beaver Bay weather station on the southern edge of our study

126 area (National Oceanic and Atmospheric Administration). Snow cover is typically present from

127 December to April, with mean annual snowfall ranging between $150-240 \mathrm{~cm}$ (Minnesota

128 Department of Natural Resources).

\section{Animal Capture and GPS Telemetry}

We captured moose by darting them from helicopters (Quicksilver Air, Inc., Fairbanks,

132 Alaska, USA) during the winters of 2011 and 2012. Darts used to sedate moose contained $1.2 \mathrm{ml}$

133 (4.0 mg ml-1) carfentanil citrate (ZooPharm, Laramie, Wyoming, USA) and $1.2 \mathrm{ml}^{-100 \mathrm{mg} \mathrm{ml}^{-}}$

$134{ }^{1}$ ) xylazine $\mathrm{HCl}$ (Midwest Veterinary Supply, Inc., Burnsville, Minnesota, USA), and we used

$1357.2 \mathrm{ml}\left(50 \mathrm{mg} \mathrm{ml}^{-1}\right)$ naltrexone $\mathrm{HCl}(\mathrm{ZooPharm})$ and $3 \mathrm{ml}\left(5 \mathrm{mg} \mathrm{ml}^{-1}\right)$ yohimbine $\mathrm{HCl}(\mathrm{Midwest}$

136 Veterinary Supply) as antagonists (Roffe et al. 2001; Lenarz et al. 2009). We fitted immobilized

137 moose with global positioning system (GPS) collars (Lotek Wireless, Inc., Newmarket, Ontario,

138 Canada). Animal capture and handling protocols met American Society of Mammalogists

139 recommended guidelines (Sikes et al 2011) and were approved by the University of Minnesota

140 Animal Care and Use Committee (Protocol Number: 1309-30915A).

141 Collars were programmed to record locations every 20 minutes and to drop off moose at

142 the end of expected battery life (2 years). We retained GPS locations with 3-D fixes or 2-D fixes

143 with dilution of precision values $\leq 5$ (Lewis et al. 2007) and removed locations that resulted in 
144 movement rates $>30 \mathrm{~km} /$ hour. Data used in this analysis include only locations between May 1

145 and September 31 - dates that coincide with average daily maximum temperatures above the

146 threshold believed to induce heat stress for moose (Renecker and Hudson 1986). Location and

147 activity data within 2 weeks of death or collar failure were censored from our data, and only full

148 months of data were used in analysis. Our analysis included 153 moose-months from 24 moose.

149 Moose were adults at capture except for one moose that was a yearling (1.8 years old), and 17 of

15024 moose were females.

\section{Model Covariates}

Because shade is difficult to directly calculate over large areas at fine scales and varies at

154 any given location on daily and seasonal cycles, we used canopy vegetation density as a proxy

155 for shade. Canopy vegetation density was estimated using airborne lidar data. Lidar is an active,

156 laser-based remote sensing technology that provides detailed information on topography and

157 vegetation structure (Vierling et al. 2008; Davies and Asner 2014). Lidar data were collected

158 over our entire study area during leaf-off conditions in May 2011 as part of the Minnesota

159 Elevation Mapping project (Minnesota Geospatial Information Office). Lidar data were collected

160 from a fixed wing airplane at an altitude of 2,000-2,300 $\mathrm{m}$ above ground level using discrete-

161 return laser scanning systems (ALS60, ALS70, or Optech GEMINI). Side overlap was 25\% with

162 a scan angle of $\pm 20^{\circ}$. Nominal point spacing and pulse density varied due to incomplete overlap

163 of adjacent flight-lines. Average nominal pulse density was $1 \mathrm{pulse} / \mathrm{m}^{2}$. We calculated height of

164 discrete returns above ground by subtracting ground elevation based on a lidar-derived Digital

165 Elevation Model from the return elevation. Lidar data met the National Standard for Spatial 
Database Accuracy (Federal Geographic Data Committee 1998) and had a vertical accuracy

RMSE of $5.0 \mathrm{~cm}$ and a horizontal accuracy of $1.16 \mathrm{~m}$.

We estimated canopy vegetation density as the proportion of all returns that were $\geq 3 \mathrm{~m}$

169 above ground. Canopy vegetation density is typically estimated with LiDAR as the ratio of

170 returns originating from the canopy to the total number of returns (Vierling et al. 2008; Merrick

171 et al. 2013; Davies and Asner 2014). We used a threshold of $3 \mathrm{~m}$ to estimate canopy vegetation

172 density because this corresponds to canopy over a moose's head. Lidar-derived canopy

173 vegetation density estimates were summarized in a 30 x $30 \mathrm{~m}$ grid that aligned with 2011

174 National Land Cover Database (NLCD; Homer et al. 2015) raster data to ensure consistency

175 across data layers in GIS. We used FUSION software (McGaughey 2016) to create the lidar-

176 derived canopy vegetation density raster. For the sake of simplicity, we hereafter refer to lidar-

177 derived canopy vegetation density as "shade".

178 Vegetation cover types were determined using the 2011 NLCD (Homer et al. 2015).

179 NLCD is a remotely sensed dataset of 16 land cover classes created from Landsat Thematic

180 Mapper with $30 \mathrm{~m}$ spatial resolution. We extracted 5 vegetation cover types that may offer

181 thermal refuge — woody wetland, hereafter called bog; emergent herbaceous wetland, hereafter

182 called marsh; open water; conifer forests; and mixed forests. Each of these cover types offers

183 different amounts of thermal refuge via different mechanisms (Table 1). Each cover type also

184 offers different amounts of forage. Since moose primarily eat the leaves of deciduous shrubs and

185 saplings $<3 \mathrm{~m}$ tall during summer (Peek et al. 1976), forage quantity decreases as the amount of

186 shade and proportion of conifers increases. Selection of cover types may be dependent on

187 proximity to other cover types, and GPS error may lead to underestimation of selection of cover

188 types covering small areas (Conner et al. 2003; Martin et al. 2018). We therefore calculated the 
189 Euclidean distance of each pixel in our study area from each of our chosen vegetation cover

190 types using ArcMap 10.4 (Esri, Redlands, California, USA). Euclidean distances were 0 when an

191 animal was within the land cover type of interest.

192 Temperature data were obtained from two weather stations within our study area-

193 KBFW in Silver Bay and KCKC in Grand Marais (Fig. A1; MesoWest). These stations are

194 operated by the National Oceanic and Atmospheric Administration according to national

195 standards and report temperatures at 20-minute intervals. Moose locations were individually

196 matched with the nearest weather station (by distance) and nearest temperature recording (by

197 time). Moose locations were on average $33 \mathrm{~km}$ from the nearest weather station and 7 minutes

198 from the closest recorded weather observation in time.

200 Statistical Analysis

201 We used a step-selection function (SSF) to model moose resource selection and

202 movement behavior. For our SSF, we selected available points using a parameterized Weibull

203 distribution of step lengths and the observed distribution of turn angles of the animals in our data

204 set. We paired 20 available locations to each used location (i.e., 21 points per stratum). Our final

205 data set contained 311,521 steps taken by 24 moose. We used conditional logistic regression (via

206 the 'clogit' function in the 'survival' package; Therneau 2019) to fit the SSF containing our

207 variables of interest (extracted at the end of each step; listed in Table 1) and interactions between

208 each variable and ambient temperature. We included step length (i.e., distance between

209 consecutive fixes) both to reduce bias in selection estimates (Forester et al. 2009) and to

210 explicitly model its interaction with another variable of interest (Avgar et al. 2016; Prokopenko

211 et al. 2017; Ladle et al. 2019). Interaction coefficients detail how temperature influences step 
212 length and selection of cover types at differing temperatures. Because step lengths vary in a

213 regular pattern over the course of each 24-hour period (Fig. A2), we adjusted step lengths prior

214 to inclusion in the model by subtracting the observed step length from the average step length at

215 each given time of day. Because moose move more during crepuscular periods than at other

216 times of day regardless of temperature (Cederlund 1989; Lowe et al. 2010; Eriksen et al. 2011;

217 Vander Vennen et al. 2016), failure to adjust for crepuscular activity peaks could lead to

218 consistent positive bias in movement rates at low (morning) and intermediate (evening)

219 temperatures. We included one-way interactions between each covariate and temperature $\left({ }^{\circ} \mathrm{C}\right)$.

220 Because temperature was constant within strata, it was considered only as an interaction term.

221 The full final model is listed below:

222

223 Use $\sim$ Shade + dBog + dMarsh + dWater + dConifer + dMixed + StepLength + Temp $*$ Shade +

224 Temp*dBog + Temp*dMarsh + Temp*dWater + Temp*dConifer + Temp*dMixed +

225 Temp*StepLength,

227 where “*” denotes interactions between variables. We used generalized estimating equations

228 (GEEs) to obtain robust standard errors among animal-days that reduce Type I error caused by

229 pseudoreplication (Fortin et al. 2005; Craiu et al. 2008; Duchesne et al. 2010), and checked that

230 variance inflation factors (VIFs) between main effects were $<3$ to ensure multicollinearity was

231 not a problem in our model (O’Brien 2007; Dormann et al. 2013). We calculated VIFs using the

232 'vif' function in the 'car' package (Fox and Weisberg 2019). We then conducted k-fold (k=5)

233 cross-validation on our final model and calculated Spearman rank correlation (mean of 50

234 replications) to evaluate model fit based on the methods of Fortin et al. (2009). Finally, we 
235 rarified data to 1-, 2-, and 4-hour intervals to demonstrate the impact of less frequent GPS

236 location data on our ability to detect biologically significant interactions. All analyses were

237 conducted using R statistical software (R Core Team 2018). Effect sizes are reported as relative

238 selection strength (RSS) for one location on the landscape relative to another, given the

239 difference in a variable of interest between the two locations while holding the values of all other

240 variables in the model constant (Avgar et al. 2017).

\section{Results}

\section{Moose Movement and Resource Selection}

244 We found empirical support for four interaction terms (StepLength*Temp, Shade*Temp,

245 dBog*Temp, dMixedForest*Temp) in our step-selection function (Table 2), indicating that

246 temperature significantly altered movement rate and selection for shade, bog, and mixed forest.

247 We did not detect empirical support for interactions between temperature and distance to marsh,

248 temperature and distance to open water, or temperature and distance to conifer forest. Of these

249 variables with interaction terms whose $95 \%$ CIs overlapped zero, only the main effect for

250 distance to conifer forest was significant. Regardless of temperature, moose selected areas

251 further from conifer forest (Relative Selection Strength $[\mathrm{RSS}]=1.553 ; 95 \% \mathrm{CI}=1.133-2.130$ ).

252 Moose neither selected nor avoided areas near marsh or open water. Habitat use by moose was

253 consistent throughout our study period (i.e., month-to-month changes in distance to vegetation

254 cover types were small; Fig. A3).

255 Moose decreased movement rates at hotter temperatures (Fig. 2A). At each standardized

256 step length $>0 \mathrm{~m}$ (i.e., steps that were longer than average for a given time of day), the odds of

257 moose taking a step of that length was higher at $0^{\circ} \mathrm{C}$ than at $15^{\circ} \mathrm{C}$, and higher at $15^{\circ} \mathrm{C}$ than at 
$30^{\circ} \mathrm{C}$. At $0^{\circ} \mathrm{C}$, the odds that moose would move $100 \mathrm{~m}$ more than average in 20 minutes were substantially higher $(\mathrm{RSS}=1.074 ; 95 \% \mathrm{CI}=1.025-1.126)$ than at $15^{\circ} \mathrm{C}(\mathrm{RSS}=0.849 ; 95 \% \mathrm{CI}=$ 0.777-0.928), which were in turn substantially higher than at $30^{\circ} \mathrm{C}(\mathrm{RSS}=0.672 ; 95 \% \mathrm{CI}=$ 0.590-0.765). Furthermore, the mean step length at all temperatures above $20^{\circ} \mathrm{C}$ was below the overall mean step length controlling for time of day. strength increased with increasing vegetative cover at $30^{\circ} \mathrm{C}$, while it decreased with increasing vegetative cover at $0^{\circ} \mathrm{C}$ and $15^{\circ} \mathrm{C}$, indicating that moose sought shade at high temperatures while avoiding it at lower temperatures. At $0^{\circ} \mathrm{C}$, the odds that moose would move into a pixel with $75 \%$ vegetative cover were substantially lower $(\mathrm{RSS}=0.265 ; 95 \% \mathrm{CI}=0.239-0.295)$ than at $15^{\circ} \mathrm{C}(\mathrm{RSS}=0.640 ; 95 \% \mathrm{CI}=0.523-0.782)$, which were in turn substantially lower than at $30^{\circ} \mathrm{C}$ $(\mathrm{RSS}=1.542 ; 95 \% \mathrm{CI}=1.148-2.073)$ $\mathrm{m})$, and higher at $15^{\circ} \mathrm{C}$ than at $30^{\circ} \mathrm{C}(\mathrm{RSS}=0.399 ; 95 \% \mathrm{CI}=0.237-0.672$ at $500 \mathrm{~m})$.

275 cold (Fig. 2D). The odds that moose were far from mixed forest were higher at $0^{\circ} \mathrm{C}(\mathrm{RSS}=$

$277 \mathrm{~m})$ or $30^{\circ} \mathrm{C}(\mathrm{RSS}=0.507 ; 95 \% \mathrm{CI}=0.302-0.852$ at $500 \mathrm{~m})$, though only the difference between

$278 \quad 0^{\circ} \mathrm{C}$ and $30^{\circ} \mathrm{C}$ was statistically significant.

\section{Model validation}


281 K-fold cross-validation of our model demonstrated that our model was substantially better than

282 random at predicting where moose moved - the mean Spearman rank correlation coefficient was

2830.47 for observed steps.

284

285 Effects of temporal scale on interactions

286 The interactions we found between temperature and step length, shade, distance to bog, and 287 distance to mixed forest diminish substantially if GPS locations are rarified so that locations 288 occur at longer intervals. When 20-min interval GPS data are rarified to 1-hr, 2-hr, and 4-hr 289 intervals and used to fit the same SSF, interactions become progressively less biologically 290 meaningful (Fig. A4). As the length of time intervals between locations increases, differences 291 across temperatures for step length, shade, and distance to bog become minimal. Differences 292 across temperatures for distance to mixed forest shrink, but more gradually.

\section{Discussion}

In this paper, we developed a modeling framework to test multiple competing (but not

296 mutually exclusive) hypotheses on behavioral responses by animals to heat. We used this

297 framework to model behavioral responses by moose, an ungulate known to be sensitive to heat

298 (Renecker and Hudson 1986; McCann et al. 2013; Melin et al. 2014). Moose altered both

299 movement and habitat selection to behaviorally thermoregulate during hot periods. Moose

300 reduced movement and moved nearer to or stayed within shade, bogs, and mixed forest at high

301 heat, even while avoiding shade and bogs at cooler temperatures (Fig. 2). This pattern links

302 previous findings of separate studies. First, moose prefer to forage in areas with low canopy

303 cover, likely because canopy cover is generally inversely related to forage availability (Lone et 
al. 2014). Second, moose prefer to use bed sites under dense forest canopy in wet lowland forests

during the day (McCann et al. 2016), where moose have access to less forage but more

protection against heat gain from solar radiation and more capacity to lose heat to wet ground via conduction. Moose therefore face a steep tradeoff during periods of heat — areas that are good for temperatures increase indicates that moose forego foraging in favor of bedding down under shade as temperatures increase. Earlier studies have documented moose shifting activity to

311 cooler evenings and nights on hot days (Dussault et al. 2004; Montgomery et al. 2019), which is

312 consistent with this trade-off.

The vegetation cover types used more by moose during warm weather further indicate

314 that moose face a tradeoff between foraging and thermoregulation during periods of heat. In

315 general, moose are more likely to find greater quantities of forage in cover types that do not

316 provide thermal cover, while cover types that provide thermal cover are less likely to provide

317 forage. For example, upland mixed forest has some available forage, but forage availability is

318 highest in this cover type in young forests with little canopy cover. Similarly, bogs in Minnesota

319 are largely populated by black spruce, tamarack, and alder, all of which can provide thermal

320 cover but are very rarely eaten by moose (Peek et al. 1976). Birch (Betula spp.), willow (Salix

321 spp.), and red-osier dogwood (Cornus sericea) are eaten by moose and occasionally grow in

322 bogs in Minnesota, but rarely at densities high enough to compensate for unpalatable species

323 dominating the canopy layer.

324 Further studies would be helpful for demonstrating how common trade-offs between

325 thermoregulation and foraging are among ungulates. Reductions in activity during periods of

326 heat are widespread among ungulates, having been documented in a diverse array of ungulates 
that include moose, mule deer (Odocoileus hemionus; Sargeant et al. 1994), white-tailed deer $(O$.

virginianus; Wolff et al. 2020), bighorn sheep (Ovis canadensis; Alderman et al. 1989), Alpine

rupricapra; Mason et al. 2014), common eland (Taurotragus oryx; Shrestha et al. 2014), black

taurinus; Shrestha et al. 2014), impala (Aepycerus melampus; Shrestha et al. 2014), and greater adequate thermal cover).

341 (Cervus canadensis) prioritize reducing thermoregulatory costs over forage quality in low-

342 elevation desert populations but not in high-elevation mountain populations, and individuals with

343 low fat reserves prioritize reducing thermoregulatory costs over forage quality most strongly

344 (Long et al. 2014). Body size may also play a role in modulating tradeoffs between foraging and

345 thermoregulation. Adult male Alpine ibex, which are substantially larger than females, reduce

346 time spent foraging more than females when it is hot (Aublet et al. 2009). Common eland and

347 blue wildebeest reduce afternoon activity all year round, but smaller impala reduce afternoon

348 activity only during the summer (Shrestha et al. 2014). The effects of environmental variation,

349 nutritional condition, or body size on thermoregulatory behavior could be answered in larger data 
sets using our modeling framework by building SSFs for each individual and testing for statistical effects of a variable of interest (e.g., fat reserves, body size) on the RSS of a variable

352 of interest (e.g., step length at a given high temperature).

354 stress will also be important in a warming future. In our study, moose used shade far more than

355 water to ameliorate heat during hot weather. Moose are commonly observed in bodies of water, and anecdotal evidence suggests that moose use water to shed heat (Schwab and Pitt 1991; Demarchi and Bunnell 1995). Our analysis, however, indicates that moose do not often use open water and marsh to mitigate heat stress; they prefer to seek shadier vegetation cover types. Nevertheless, they do increase use of woody bogs — where both shade and some water are usually available — as temperatures increase. This is consistent with a previous study (McCann et al. 2016) that found that moose prefer bed sites with both canopy cover and relatively high soil moisture. Other ungulates may use different features of the landscape to mitigate heat stress. For example, mountain goats (Oreamnos americanus) may move closer to persistent snow cover

364 during hot weather rather than seeking shade (Sarmento et al. 2019). Step-selection functions 365 that include interactions with temperature offer a simple way to test for the relative importance 366 of a wide variety of different landscape features for thermoregulation. relationship between temperature and movement rates (Dussault et al. 2004; Montgomery et al.

370 2019). Moose spend about half of the day foraging during the summer, with foraging bouts

371 interspersed by periods of rumination at bed sites. Periods of rest and rumination are typically

372 distinct and occur at regular intervals of roughly 2 hours (Renecker and Hudson 1989; Moen et 
373 al. 1996). As the interval between GPS locations increases, the chance that both ambulatory

374 foraging bouts and stationary ruminating bouts are aggregated into a single GPS fix increases,

375 which homogenizes step lengths (Moen et al. 1996). Frequent GPS locations reduce the

376 probability of this happening. Indeed, when our location data was rarified to 1-, 2-, and 4-hour

377 intervals, effect sizes of interactions between temperature and movement rates were

378 progressively reduced (Fig. A4). Because many species have idiosyncratic movement behaviors,

379 movement studies may require intervals between GPS locations within a specific range to best

380 answer research questions concerning animal movement. This is an important consideration for

381 researchers planning studies of animal movement. Researchers should carefully consider the

382 frequency of GPS locations before deploying GPS collars and recognize that GPS data that is too

383 sparse may result in Type II error.

384 Our analysis can directly inform management and conservation actions for wildlife.

385 Many moose populations at the southern edge of their distribution (including our study area)

386 have undergone substantial declines in the past decade (Lenarz et al. 2010; van Beest et al. 2012;

387 Dou et al. 2013; Monteith et al. 2015). Our results suggest that in a warmer future proximity to

388 shade will strongly influence habitat suitability for moose in areas with abundant forage due to

389 timber harvest and other anthropogenic disturbance. Moose will likely benefit from management

390 action to explicitly promote maintenance of shade near large patches of forage. Because moose

391 prioritize shade over forage when it is hot, moose will likely not feed in large forest openings on

392 hot days (though moose may feed in unshaded forest openings at night; Dussault et al. 2004).

393 Moose will likely spend more time foraging in forest openings with patches of canopy cover than

394 in large homogeneous forest openings. For example, most of the forage in large clearcuts may be

395 inaccessible to moose during hot periods unless the clearcuts contain "reserve patches", or 
interior islands or fingers of forest extending into the clearcut. These reserve patches will likely be most helpful for moose if they consist of bog or mixed forest. behavioral strategies to a population-level response to large-scale drivers like climate change. Although behavioral thermoregulation mitigates some metabolic costs of hot weather, forgoing

401 foraging to avoid high body temperatures may result in decreased fat reserves, lower fitness, and ultimately in population declines compared to a cooler baseline scenario where moose do not need to behaviorally thermoregulate. Although we did not link behavior to fitness in this study, identifying and quantifying patterns of behavior allows researchers to explicitly test for effects on fitness in subsequent studies. For example, development of conceptual and modeling

406 frameworks to identify and quantify "green wave surfing" behavior (by which animals migrate 407 along paths of rapidly greening forage) in migratory ungulates (Bischof et al. 2012; Merkle et al. 408 2016; Aikens et al. 2017) allowed researchers to later quantify a connection between green wave 409 surfing and fitness (Middleton et al. 2018). Our study could be used as a foundation for further 410 analyses along these lines, or to parameterize mechanistic models of moose energetic balances 411 under various climate scenarios, land management strategies, or disturbance regimes to project 412 the outcomes of conservation actions taken to benefit moose. Our analysis demonstrates that advances in animal tracking, remote sensing, and

414 modelling techniques allow us to study responses by free-ranging animals to weather in the field

415 at finer scales than previously possible. SSFs in particular are a valuable tool to answer questions

416 concerning behavioral responses by free-ranging animals to changes in weather in a relatively

417 simple and intuitive way. Because SSFs estimate selection conditionally at each GPS location, 418 each location or step can be connected with a distinct time and spatial location, enabling 
419 inference on how animals change movement and habitat selection in space and time in response

420 to specific stimuli. SSFs have been used to characterize animal movements in relation to

421 landscape features, such as grizzly bear (Ursus arctos) response to human activity (Ladle et al.

422 2019) and North American elk, African wild dog (Lycaon pictus), and wolverine (Gulo gulo)

423 response to roads (Abrahms et al. 2016; Prokopenko et al. 2017; Scrafford et al. 2018). Likewise,

424 SSFs that incorporate interactions between temperature and other variables of interest can

425 characterize changes in movement behavior and habitat use in response to differences in

426 temperature.

427 In conclusion, moose altered both movement and habitat selection to behaviorally

428 thermoregulate during hot periods by reducing movement rates and increasing use of shaded

429 vegetation cover types that they avoided at cooler temperatures. Moose did not regularly use

430 water sources that lack canopy cover to shed heat. Moose face a tradeoff between forage and

431 thermal cover at high temperatures and forego foraging in favor of seeking thermal cover.

432 Behavior changed at thresholds near (though somewhat above) previously documented heat

433 stress thresholds (Renecker and Hudson 1986; McCann et al. 2013): step lengths decreased at

434 temperatures above $20^{\circ} \mathrm{C}$, and selection patterns for shade reversed above $15^{\circ} \mathrm{C}$. Future research

435 characterizing strategies for behavioral thermoregulation and consequences of those strategies

436 for fitness will aid conservation in a warming world, for both moose and other heat-sensitive

437 species.

439 Acknowledgements

440 Many thanks to B. Olson, W. Chen, and others who helped collect field data, as well as J. Rick,

441 B. Brito, F. Molina, B. Maitland, S. Esmaeili, and J. Goheen for providing helpful comments on 
442 early drafts of this manuscript. This study was funded by Minnesota's Environmental and Natural

443 Resources Trust Fund, the University of Minnesota-Duluth Integrated Biosciences graduate

444 program, and the University of Wyoming Department of Zoology and Physiology.

445

446 Author Contributions

447 JA and RM conceived and designed the study; RM collected the data; JA, MJ, and JM analyzed

448 the data; JA led the writing of the manuscript. All authors contributed critically to manuscript

449 drafts and gave final approval for publication.

450

451 Data Availability

452 Data and R scripts are archived on Zenodo at: http://doi.org/10.5281/zenodo.3872407.

\section{References}

455 Abrahms B, Jordan NR, Golabek KA, et al (2016) Lessons from integrating behaviour and

456 resource selection: activity-specific responses of African wild dogs to roads. Anim

457 Conserv 19:247-255. https://doi.org/10.1111/acv.12235

458 Aikens EO, Kauffman MJ, Merkle JA, et al (2017) The greenscape shapes surfing of resource

459 waves in a large migratory herbivore. Ecol Lett 20:741-750.

460 https://doi.org/10.1111/ele.12772

461 Alderman JA, Krausman PR, Leopold BD (1989) Diel activity of female desert bighorn sheep in 
Aublet J-F, Festa-Bianchet M, Bergero D, Bassano B (2009) Temperature constraints on 247. https://doi.org/10.1007/s00442-008-1198-4

Avgar T, Lele SR, Keim JL, Boyce MS (2017) Relative selection strength: quantifying effect size in habitat- and step-selection inference. Ecol Evol 7:5322-5330. https://doi.org/10.1002/ece3.3122

Avgar T, Potts JR, Lewis MA, Boyce MS (2016) Integrated step selection analysis: bridging the gap between resource selection and animal movement. Meth Ecol Evol 7:619-630. https://doi.org/10.1111/2041-210X.12528

Bartholomew GA, Dawson WR (1979) Thermoregulatory behavior during incubation in Heermann's gulls. Physiol Zool 52:422-437. https://doi.org/10.1007/BF00346984

Bischof R, Loe LE, Meisingset EL, et al (2012) A migratory northern ungulate in the pursuit of spring: jumping or surfing the green wave? Am Nat 180:407-424.

Boyles JG, Seebacher F, Smit B, McKechnie AE (2011) Adaptive thermoregulation in endotherms may alter responses to climate change. Integr Comp Biol 51:676-690. https://doi.org/10.1093/icb/icr053 
Campos FA, Fedigan LM (2009) Behavioral adaptations to heat stress and water scarcity in white-faced capuchins (Cebus capucinus) in Santa Rosa National Park, Costa Rica. Am J Phys Anthropol 138:101-111. https://doi.org/10.1002/ajpa.20908

Cederlund G (1989) Activity patterns in moose and roe deer in a north boreal forest. Ecography

Conner LM, Smith MD, Burger LW (2003) A comparison of distance-based and classificationbased analyses of habitat use. Ecology 84:526-531. https://doi.org/10.1890/00129658(2003)084[0526:ACODBA]2.0.CO;2

493 Cowles RB, Bogert CM (1944) A preliminary study of the thermal requirements of desert reptiles. Bull Am Nat Hist 83:261-296 model with longitudinal data. Biometrical J 50:97-109. https://doi.org/10.1002/bimj.200610379

Davies AB, Asner GP (2014) Advances in animal ecology from 3D-LiDAR ecosystem mapping. Trends Ecol Evol 29:681-691. https://doi.org/10.1016/j.tree.2014.10.005

Demarchi MW, Bunnell FL (1995) Forest cover selection and activity of cow moose in summer. Acta Theriol 40:23-36

Dormann CF, Elith J, Bacher S, et al (2013) Collinearity: a review of methods to deal with it and a simulation study evaluating their performance. Ecography 36:27-46. https://doi.org/10.1111/j.1600-0587.2012.07348.x

505 Dou H, Jiang G, Stott P, Piao R (2013) Climate change impacts population dynamics and distribution shift of moose (Alces alces) in Heilongjiang Province of China. Ecol Res 28:625-632. https://doi.org/10.1007/s11284-013-1054-9 
Duchesne T, Fortin D, Courbin N (2010) Mixed conditional logistic regression for habitat selection studies. J Anim Ecol 79:548-555. https://doi.org/10.1111/j.13652656.2010.01670.x

Duchesne T, Fortin D, Rivest L-P (2015) Equivalence between step selection functions and biased correlated random walks for statistical inference on animal movement. PLOS ONE 10:e0122947. https://doi.org/10.1371/journal.pone.0122947

Dussault C, Ouellet J-P, Courtois R, et al (2004) Behavioural responses of moose to thermal conditions in the boreal forest. Écoscience 11:321-328

Eriksen A, Wabakken P, Zimmermann B, et al (2011) Activity patterns of predator and prey: a simultaneous study of GPS-collared wolves and moose. Anim Behav 81:423-431. https://doi.org/10.1016/j.anbehav.2010.11.011

Federal Geographic Data Committee (1998) National Standard for spatial data accuracy (NSSDA). Federal Geographic Data Committee, Washington, D.C., U.S.A.

Forester JD, Im HK, Rathouz PJ (2009) Accounting for animal movement in estimation of resource selection functions: sampling and data analysis. Ecology 90:3554-3565.

Fortin D, Beyer HL, Boyce MS, et al (2005) Wolves influence elk movements: behavior shapes a trophic cascade in Yellowstone National Park. Ecology 86:1320-1330.

527 Fortin D, Fortin M-E, Beyer HL, et al (2009) Group-size-mediated habitat selection and group fusion-fission dynamics of bison under predation risk. Ecology 90:2480-2490. https://doi.org/10.1890/08-0345.1 
530 Fox J, Weisberg S (2019) An R companion to applied regression, Third. Sage, Thousand Oaks, CA, USA

532 Hoegh-Guldberg O, Bruno JF (2010) The impact of climate change on the world's marine ecosystems. Science 328:1523-1528. https://doi.org/10.1126/science.1189930

534 Homer C, Dewitz J, Yang L, et al (2015) Completion of the 2011 National Land Cover Database for the conterminous United States-representing a decade of land cover change

Hovick TJ, Elmore RD, Allred BW, et al (2014) Landscapes as a moderator of thermal extremes: a case study from an imperiled grouse. Ecosphere 5:1-12. https://doi.org/10.1890/ES1300340.1

Kurylyk BL, MacQuarrie KTB, Linnansaari T, et al (2015) Preserving, augmenting, and creating cold-water thermal refugia in rivers: concepts derived from research on the Miramichi

544 Ladle A, Avgar T, Wheatley M, et al (2019) Grizzly bear response to spatio-temporal variability River, New Brunswick (Canada). Ecohydrology 8:1095-1108.

547 Lenarz MS, Fieberg J, Schrage MW, Edwards AJ (2010) Living on the edge: viability of moose in northeastern Minnesota. J Wildl Manage 74:1013-1023. https://doi.org/10.2193/2009-

550 Lenarz MS, Nelson ME, Schrage MW, Edwards AJ (2009) Temperature mediated moose survival in northeastern Minnesota. J Wildl Manage 73:503-510. https://doi.org/10.2193/2008-265 
553 Lewis JS, Rachlow JL, Garton EO, Vierling LA (2007) Effects of habitat on GPS collar

554 performance: using data screening to reduce location error. J Appl Ecol 44:663-671. https://doi.org/10.1111/j.1365-2664.2007.01286.x

556 Lone K, Beest FM van, Mysterud A, et al (2014) Improving broad scale forage mapping and habitat selection analyses with airborne laser scanning: the case of moose. Ecosphere

Long RA, Bowyer RT, Porter WP, et al (2014) Behavior and nutritional condition buffer a largebodied endotherm against direct and indirect effects of climate. Ecol Monogr 84:513-

Lowe SJ, Patterson BR, Schaefer JA (2010) Lack of behavioral responses of moose (Alces alces) to high ambient temperatures near the southern periphery of their range. Can J Zool

Luskick S, Battersby B, Kelty M (1978) Behavioral thermoregulation: orientation toward the sun 88:1032-1041. https://doi.org/10.1139/Z10-071

Martin J, Vourc'h G, Bonnot N, et al (2018) Temporal shifts in landscape connectivity for an ecosystem engineer, the roe deer, across a multiple-use landscape. Landsc Ecol 33:937-

Mason THE, Brivio F, Stephens PA, et al (2017) The behavioral trade-off between thermoregulation and foraging in a heat-sensitive species. Behav Ecol 28:908-918. https://doi.org/10.1093/beheco/arx057

573 Mason THE, Stephens PA, Apollonio M, Willis SG (2014) Predicting potential responses to future climate in an alpine ungulate: interspecific interactions exceed climate effects. Glob Change Biol 20:3872-3882. https://doi.org/10.1111/gcb.12641 
McCann NP, Moen RA, Harris TR (2013) Warm-season heat stress in moose (Alces alces). Can J Zool 91:893-898. https://doi.org/10.1139/cjz-2013-0175

McCann NP, Moen RA, Windels SK, Harris TR (2016) Bed sites as thermal refuges for a coldadapted ungulate in summer. Wildl Biol 22:228-237. https://doi.org/10.2981/wlb.00216

McGaughey RJ (2016) FUSION/LDV: Software for LIDAR data analysis and visualization. US Department of Agriculture, Forest Service, Pacific Northwest Research Station, Seattle,

Melin M, Matala J, Mehtätalo L, et al (2014) Moose (Alces alces) reacts to high summer temperatures by utilizing thermal shelters in boreal forests - an analysis based on airborne laser scanning of the canopy structure at moose locations. Glob Change Biol

Merkle JA, Monteith KL, Aikens EO, et al (2016) Large herbivores surf waves of green-up during spring. Proc Royal Soc Lond B: Biol Sci 283:20160456.

Merrick MJ, Koprowski JL, Wilcox C (2013) Into the third dimension: benefits of incorporating LiDAR data in wildlife habitat models. In: Merging science and management in a rapidly changing world: biodiversity and management of the Madrean Archipelago III and 7th Accessed 27 Apr 2018 conference on research and resource management in the southwestern deserts, Rocky

Middleton AD, Merkle JA, McWhirter DE, et al (2018) Green-wave surfing increases fat gain in a migratory ungulate. Oikos 127:1060-1068. https://doi.org/10.1111/oik.05227 
Minnesota Department of Natural Resources. In: Minnesota Normal Annual Snowfall: 1981-

600

601

602

603

604

605

606

607

608

609

610 2010. https://www.dnr.state.mn.us/climate/summaries_and_publications/normals_snow_1981_ 2010.html. Accessed 27 Apr 2018

Minnesota Geospatial Information Office. http://www.mngeo.state.mn.us/committee/elevation/mn_elev_mapping.html. Accessed 27 Apr 2018

Moen R, Pastor J, Cohen Y, Schwartz CC (1996) Effects of moose movement and habitat use on GPS collar performance. J Wildl Manage 60:659-668. https://doi.org/10.2307/3802085

Monteith KL, Klaver RW, Hersey KR, et al (2015) Effects of climate and plant phenology on recruitment of moose at the southern extent of their range. Oecologia 178:1137-1148. https://doi.org/10.1007/s00442-015-3296-4

Montgomery RA, Redilla KM, Moll RJ, et al (2019) Movement modeling reveals the complex nature of the response of moose to ambient temperatures during summer. J Mammal 100:169-177. https://doi.org/10.1093/jmammal/gyy185

National Oceanic and Atmospheric Administration. In: Data Tools: 1981-2010 Normals. https://www.ncdc.noaa.gov/cdo-web/datatools/normals. Accessed 27 Apr 2018

O’Brien RM (2007) A caution regarding rules of thumb for variance inflation factors. Qual Quant 41:673-690. https://doi.org/10.1007/s11135-006-9018-6

Owen-Smith N (1998) How high ambient temperature affects the daily activity and foraging time of a subtropical ungulate, the greater kudu (Tragelaphus strepsiceros). J Zool 246:183192. https://doi.org/10.1111/j.1469-7998.1998.tb00147.x 
621 Parmesan C (2006) Ecological and evolutionary responses to recent climate change. Annu Rev

623 Pastor J, Mladenoff DJ (1992) The southern boreal-northern hardwood forest border: a systems analysis of the global boreal forest. Cambridge University Press, Cambridge, UK

Peek JM, Urich DL, Mackie RJ (1976) Moose habitat selection and relationships to forest management in northeastern Minnesota. Wildl Monogr 3-65

Pörtner HO, Farrell AP (2008) Physiology and climate change. Science 322:690-692. https://doi.org/10.1126/science.1163156

629 Prokopenko CM, Boyce MS, Avgar T (2017) Characterizing wildlife behavioural responses to roads using integrated step selection analysis. J Appl Ecol 54:470-479.

R Core Team (2018) R: a language and environment for statistical computing. R Foundation for Statistical Computing, Vienna, Austria

634 Renecker LA, Hudson RJ (1986) Seasonal energy expenditures and thermoregulatory responses of moose. Can J Zool 64:322-327. https://doi.org/10.1139/z86-052

636 Renecker LA, Hudson RJ (1989) Seasonal activity budgets of moose in aspen-dominated boreal forests. J Wildl Manage 53:296-302. https://doi.org/10.2307/3801126

638 Roffe TJ, Coffin K, Berger J (2001) Survival and immobilizing moose with carfentanil and xylazine. Wildl Soc Bull 29:1140-1146

640 Sargeant GA, Eberhardt LE, Peek JM (1994) Thermoregulation by mule deer (Odocoileus 
643 Sarmento W, Biel M, Berger J (2019) Seeking snow and breathing hard - behavioral tactics in

644 high elevation mammals to combat warming temperatures. PLOS One 14:.

645 https://doi.org/10.1371/journal.pone.0225456

646 Schwab FE, Pitt MD (1991) Moose selection of canopy cover types related to operative

647 temperature, forage, and snow depth. Can J Zool 69:3071-3077.

$648 \quad$ https://doi.org/10.1139/z91-431

649 Scrafford MA, Avgar T, Heeres R, Boyce MS (2018) Roads elicit negative movement and

650 habitat-selection responses by wolverines (Gulo gulo luscus). Behav Ecol 29:534-542.

651 https://doi.org/10.1093/beheco/arx182

652 Shrestha AK, van Wieren SE, van Langevelde F, et al (2014) Larger antelopes are sensitive to

653 heat stress throughout all seasons but smaller antelopes only during summer in an African

654 semi-arid environment. Int J Biometeorol 58:41-49. https://doi.org/10.1007/s00484-012-

$655 \quad 0622-y$

656 Signer J, Fieberg J, Avgar T (2019) Animal movement tools (amt): R package for managing

657 tracking data and conducting habitat selection analyses. Ecol Evol 9:880-890.

658 https://doi.org/10.1002/ece3.4823

659 Sikes RS, Animal Care and Use Committee of the American Society of Mammalogists (2011)

6602011 guidelines of the American Society of Mammalogists for the use of wild mammals

661 in research and education. J Mammal 92:235-253.

662 https://doi.org/10.1093/jmammal/gyw078

663 Stelzner JK (1988) Thermal effects on movement patterns of yellow baboons. Primates 29:91-

664 105. https://doi.org/10.1007/BF02380852 
Street GM, Fieberg J, Rodgers AR, et al (2016) Habitat functional response mitigates reduced foraging opportunity: implications for animal fitness and space use. Landsc Ecol 31:1939-1953. https://doi.org/10.1007/s10980-016-0372-z

Street GM, Rodgers AR, Fryxell JM (2015) Mid-day temperature variation influences seasonal habitat selection by moose. J Wildl Manage 79:505-512. https://doi.org/10.1002/jwmg.859

Sunday JM, Bates AE, Kearney MR, et al (2014) Thermal-safety margins and the necessity of thermoregulatory behavior across latitude and elevation. Proc Natl Acad Sci USA 201316145. https://doi.org/10.1073/pnas.1316145111

Therneau TM (2019) A Package for Survival in R. Version 3.1-10URL https://CRAN.Rproject.org/package $=$ survival

Thurfjell H, Ciuti S, Boyce MS (2014) Applications of step-selection functions in ecology and conservation. Move Ecol 2:4. https://doi.org/10.1186/2051-3933-2-4

van Beest FM, Van Moorter B, Milner JM (2012) Temperature-mediated habitat use and selection by a heat-sensitive northern ungulate. Anim Behav 84:723-735. https://doi.org/10.1016/j.anbehav.2012.06.032 daily variation in wolf kill rates on moose. Funct Ecol 30:1568-1573.

684 Vierling KT, Vierling LA, Gould WA, et al (2008) Lidar: shedding new light on habitat 
687 Vrahimis S, Kok OB (1993) Daily activity of black wildebeest in a semi-arid environment. Afr J Ecol 31:328-336. https://doi.org/10.1111/j.1365-2028.1993.tb00545.x

689 Walther G-R, Post E, Convey P, et al (2002) Ecological responses to recent climate change.

$690 \quad$ Nature 416:389-395. https://doi.org/10.1038/416389a

691 Wolff CL, Demarais S, Brooks CP, Barton BT (2020) Behavioral plasticity mitigates the effect 692 of warming on white-tailed deer. Ecol Evol 10:2579-2587. 


\section{Figures}

695 Fig. 1 The physical characteristics of the surrounding environment greatly influence the thermal landscape for animals. Fig. 1A

696 represents an environment (conifer forest) where heat gain may be decreased by reducing exposure to radiation, Fig. 1B represents an

697 environment (marsh) where heat loss may be increased by conduction, and Fig. 1C represents an environment (clear cut) that offers

698 neither relief from radiation nor opportunities to disperse heat via conduction. Moose likely face tradeoffs between forage availability

699 and thermal relief.

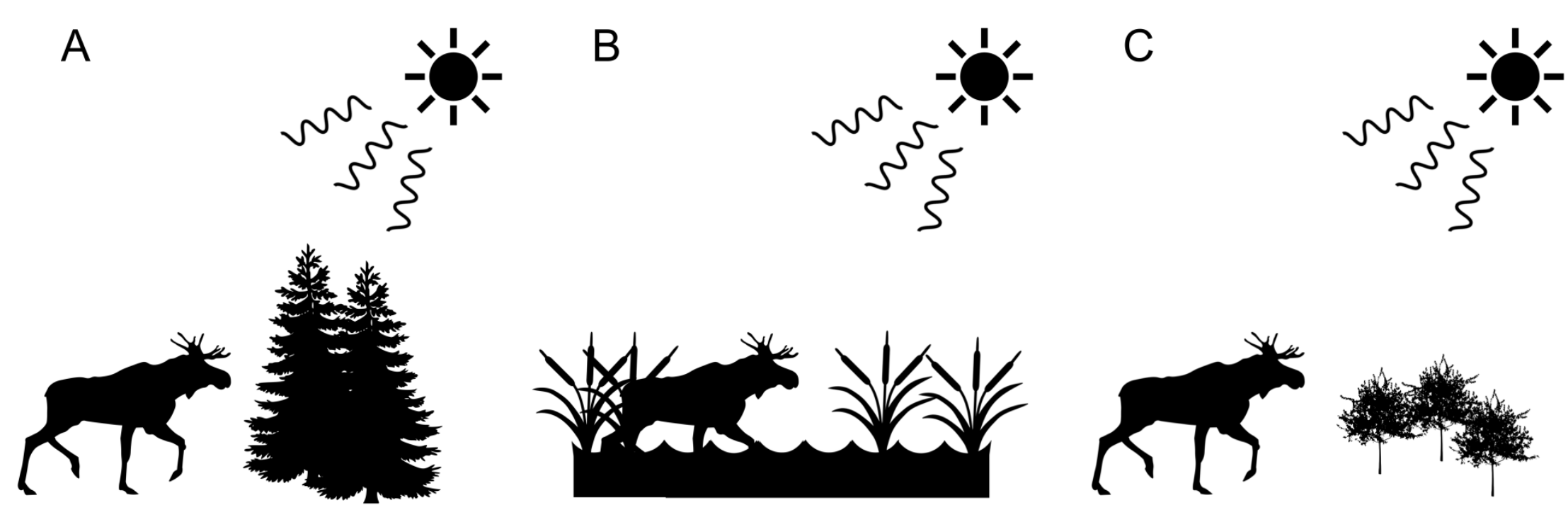


Fig. 2 Interaction plots showing relationships for significant interactions between temperature and relative selection strengths (RSS) of

703 variables of interest (A: Step length and temperature, B: Shade and temperature, C: Distance to bog and temperature, D: Distance to

704 mixed forest and temperature). High temperatures decrease the odds of longer step lengths, increase the odds of seeking shade, and

705 increase the odds of traveling in bogs and mixed forest. In some cases (A, B, and C), patterns of behavior at low temperatures reversed

706 into patterns of the opposite behavior at high temperatures (e.g., moose strongly avoid shade at $0^{\circ} \mathrm{C}$ while strongly selecting for shade

707 at $\left.30^{\circ} \mathrm{C}\right)$.
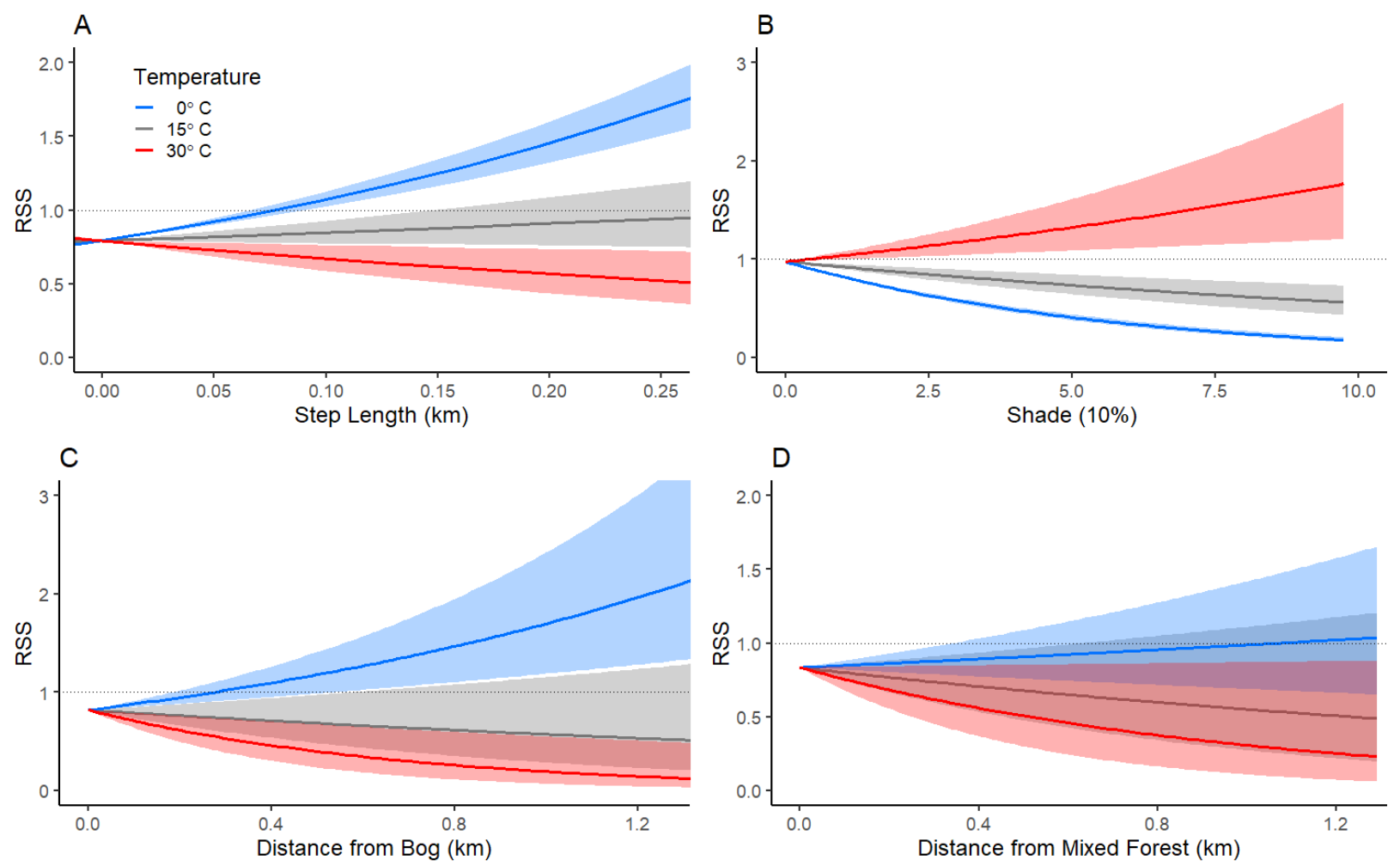


\section{Tables}

710 Table 1 Variables incorporated in the step-selection function of moose movement and habitat selection in response to changes in

711 temperature and justification for inclusion in the model.

\begin{tabular}{|c|c|c|}
\hline Name & Variable & Description \\
\hline Shade & Canopy Vegetation Density & $\begin{array}{l}\text { Proportion of all lidar returns above } 3 \text { meters; analogous to canopy vegetation density, a } \\
\text { proxy for shade }\end{array}$ \\
\hline dBog & Distance to Bog & $\begin{array}{l}\text { Distance to woody wetlands; included in analyses because bogs have both canopy cover } \\
\text { and ground moisture }\end{array}$ \\
\hline dMarsh & Distance to Marsh & $\begin{array}{l}\text { Distance to emergent herbaceous wetlands; included in analyses because moose are } \\
\text { often observed in marshes, and water can disperse heat via conduction, convection, and } \\
\text { evaporation }\end{array}$ \\
\hline dWater & Distance to Open Water & $\begin{array}{l}\text { Distance to open water; included in analyses because moose are often seen in bodies of } \\
\text { water, which can disperse heat via conduction, convection, and evaporation }\end{array}$ \\
\hline dConifer & Distance to Conifer Forest & $\begin{array}{l}\text { Distance to conifer forest; included in analyses because conifer forest contains localized } \\
\text { thick canopy cover }\end{array}$ \\
\hline dMixed & Distance to Mixed Forest & $\begin{array}{l}\text { Distance to mixed forest; included in analyses because conifers offer localized thick } \\
\text { canopy cover while deciduous trees offer foraging opportunities }\end{array}$ \\
\hline StepLength & Step Length & $\begin{array}{l}\text { Distance between a moose location and the location immediately prior; included in } \\
\text { analyses to account for bias in the parametric distribution of step lengths used to } \\
\text { characterize available points and to estimate how temperature affects movement rates }\end{array}$ \\
\hline Temp & Temperature & $\begin{array}{l}\text { Temperature at the nearest NOAA weather station at the time of a location; included in } \\
\text { analyses to estimate how temperature affects habitat use and movement rates }\end{array}$ \\
\hline
\end{tabular}


Table 2 Coefficient estimates, standard errors (SE), relative selection strengths (RSS), 95\% confidence limits (lower, LCL; upper,

UCL), and p-values for a step-selection function of moose habitat selection and movement in response to changing temperature. Bold lettering denotes variables with confidence limits that do not overlap 1 (the dividing line between selection and avoidance). Variables are described in detail in Table 1.

\begin{tabular}{lrrrrrr}
\hline Variable & Coefficient & \multicolumn{1}{l}{$\boldsymbol{S E}$} & \multicolumn{1}{l}{$\boldsymbol{R S S}$} & $\boldsymbol{L} \boldsymbol{C L}$ & \multicolumn{1}{l}{$\boldsymbol{U} \boldsymbol{L}$} & \multicolumn{1}{c}{$\boldsymbol{p}$} \\
\hline Shade & $\mathbf{- 0 . 1 7 4}$ & $\mathbf{0 . 0 0 7}$ & $\mathbf{0 . 8 4 0}$ & $\mathbf{0 . 8 2 9}$ & $\mathbf{0 . 8 5 2}$ & $<\mathbf{0 . 0 0 1}$ \\
dBog & $\mathbf{0 . 7 2 8}$ & $\mathbf{0 . 1 8 2}$ & $\mathbf{2 . 0 7 1}$ & $\mathbf{1 . 4 5 0}$ & $\mathbf{2 . 9 5 6}$ & $<\mathbf{0 . 0 0 1}$ \\
dMarsh & -0.055 & 0.108 & 0.947 & 0.767 & 1.169 & 0.612 \\
dWater & 0.057 & 0.106 & 1.058 & 0.860 & 1.302 & 0.592 \\
dConifer & $\mathbf{0 . 4 4 0}$ & $\mathbf{0 . 1 6 1}$ & $\mathbf{1 . 5 5 3}$ & $\mathbf{1 . 1 3 3}$ & $\mathbf{2 . 1 3 0}$ & $\mathbf{0 . 0 0 6}$ \\
dMixed & 0.169 & 0.184 & 1.184 & 0.825 & 1.699 & 0.359 \\
StepLength & $\mathbf{3 . 0 2 5}$ & $\mathbf{0 . 2 4 2}$ & $\mathbf{2 0 . 6 0 3}$ & $\mathbf{1 2 . 8 3 1}$ & $\mathbf{3 3 . 0 8 2}$ & $<\mathbf{0 . 0 0 1}$ \\
Shade*Temp & $\mathbf{0 . 0 0 8}$ & $\mathbf{0 . 0 0 0}$ & $\mathbf{1 . 0 0 8}$ & $\mathbf{1 . 0 0 7}$ & $\mathbf{1 . 0 0 9}$ & $<\mathbf{0 . 0 0 1}$ \\
dBog*Temp & $\mathbf{- 0 . 0 7 2}$ & $\mathbf{0 . 0 1 2}$ & $\mathbf{0 . 9 3 0}$ & $\mathbf{0 . 9 0 9}$ & $\mathbf{0 . 9 5 2}$ & $<\mathbf{0 . 0 0 1}$ \\
dMarsh*Temp & 0.004 & 0.007 & 1.004 & 0.990 & 1.019 & 0.558 \\
dWater*Temp & -0.004 & 0.007 & 0.996 & 0.982 & 1.010 & 0.589 \\
dConifer*Temp & -0.009 & 0.010 & 0.991 & 0.972 & 1.011 & 0.388 \\
dMixed*Temp & $\mathbf{- 0 . 0 3 9}$ & $\mathbf{0 . 0 1 2}$ & $\mathbf{0 . 9 6 2}$ & $\mathbf{0 . 9 4 0}$ & $\mathbf{0 . 9 8 4}$ & $\mathbf{0 . 0 0 1}$ \\
StepLength*Temp & $\mathbf{- 0 . 1 5 6}$ & $\mathbf{0 . 0 1 4}$ & $\mathbf{0 . 8 5 5}$ & $\mathbf{0 . 8 3 2}$ & $\mathbf{0 . 8 7 9}$ & $<\mathbf{0 . 0 0 1}$ \\
\hline
\end{tabular}




\section{Appendix A: Supplementary Data}

Fig. A1 Comparison of temperatures at the two weather stations used in this study (KCKC in Grand Marais and KBFW in Silver Bay).

The red line indicates a 1:1 relationship. Temperatures at $\mathrm{KCKC}$ followed the regression line $1.74+0.821 * \mathrm{KBFW}$, where "KBFW" indicates the temperature at the KBFW station. $\mathrm{R}^{2}=0.881$ for the regression equation. Temperatures were thus slightly warmer at $\mathrm{KCKC}$ at very low temperatures (less than $\sim 2^{\circ} \mathrm{C}$ ), but usually slightly cooler (e.g., when it was $30^{\circ} \mathrm{C}$ at $\mathrm{KBFW}$, the expected temperature at $\mathrm{KCKC}$ was $26.4^{\circ} \mathrm{C}$ ). Variation in temperature across our study area was thus much smaller than temperature across the day or summer.

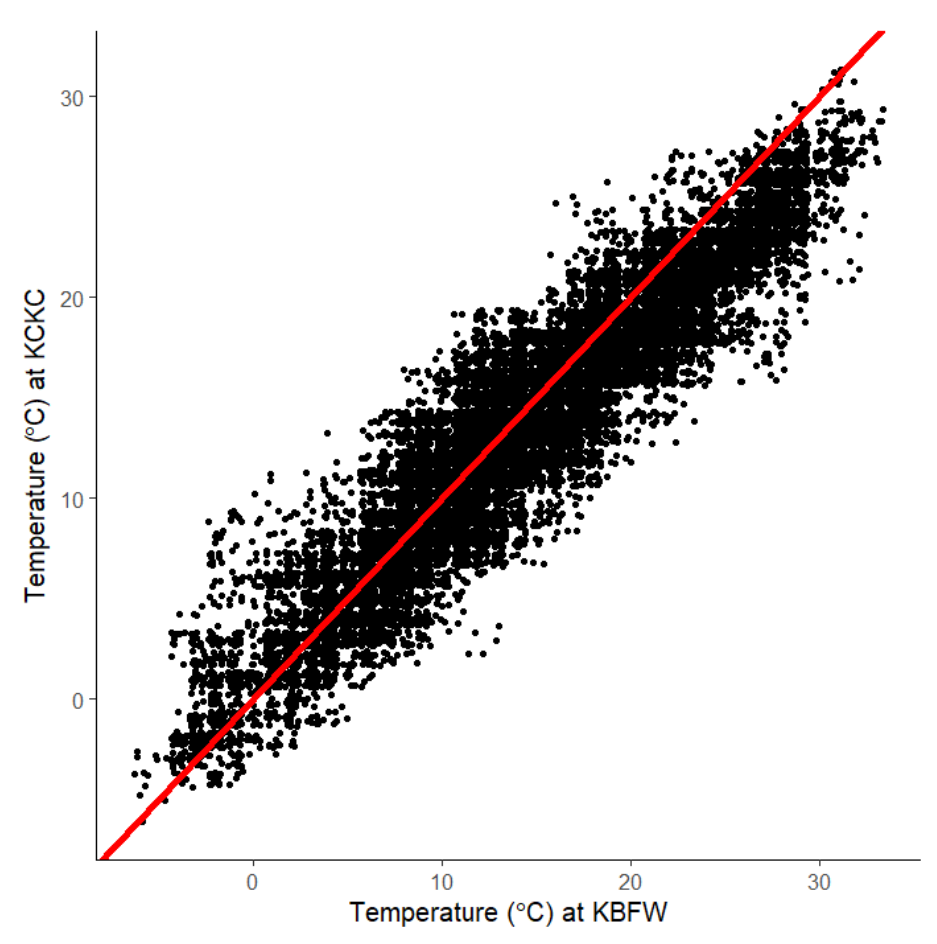


Fig. A2 Lowess regression of mean step length across times of day (20 min. increments). The gray ribbon represents the $95 \%$

confidence interval for the regression line. Moose movement rates varied slightly but consistently over the course of the day, with movement rates peaking during crepuscular periods. The area within the dotted rectangles represents the range of civil sunrise and sunset at the centroid of our study area during our study period (determined using the NOAA Solar Calculator tool [https://www.esrl.noaa.gov/gmd/grad/solcalc/]).

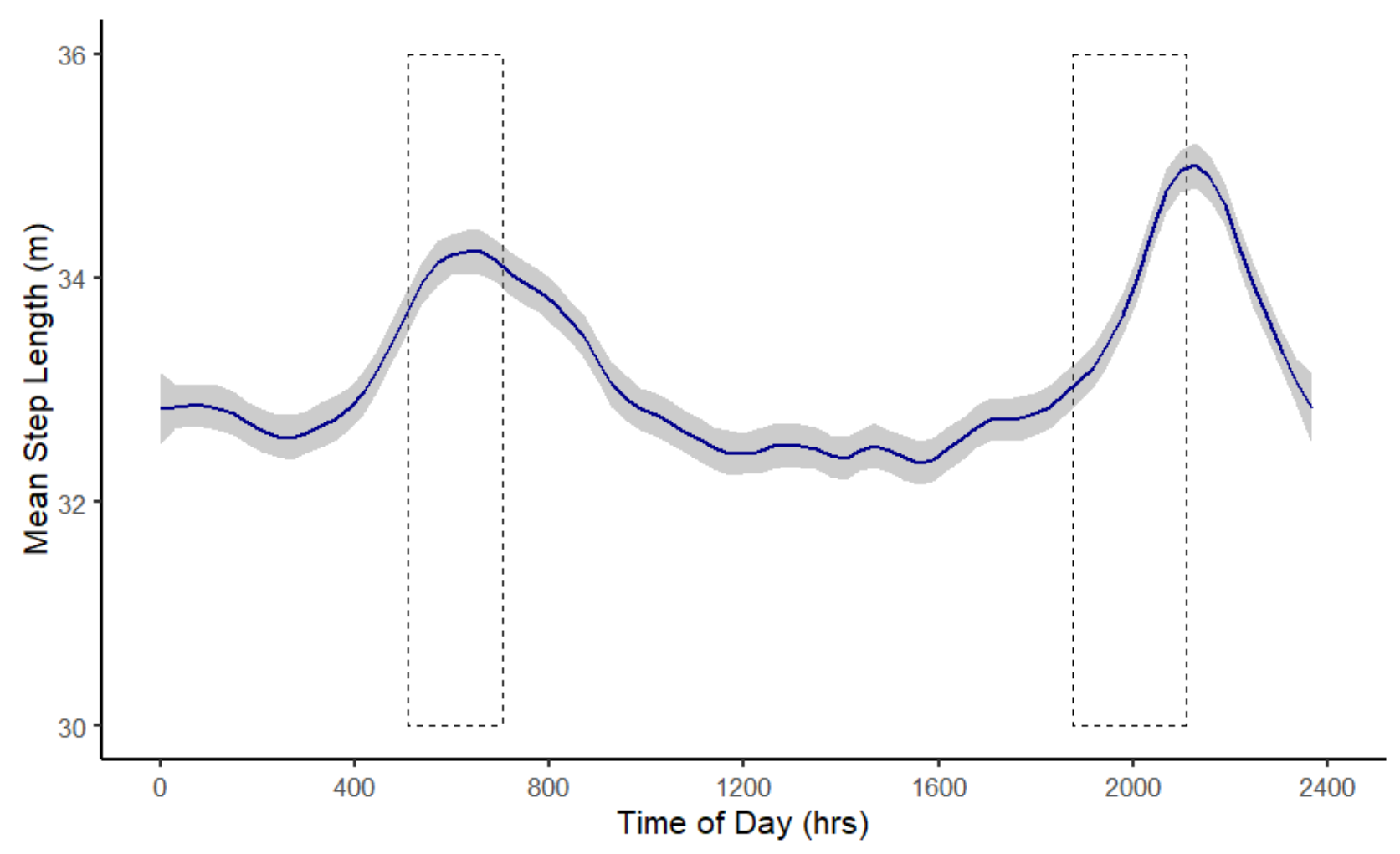


Fig. A3 Boxplots showing monthly changes in distance to cover types of interest (A: Distance to bog, B: Distance to marsh, C:

Distance to water, D: Distance to conifer forest, E: Distance to mixed forest). Month-to-month differences in habitat use are small, indicating that patterns observed from our SSF reflect habitat selection throughout our study period and are not influenced by one-time phenological events occurring during our study period (e.g., parturition movements by females during May, or the emergence of aquatic plants during June).
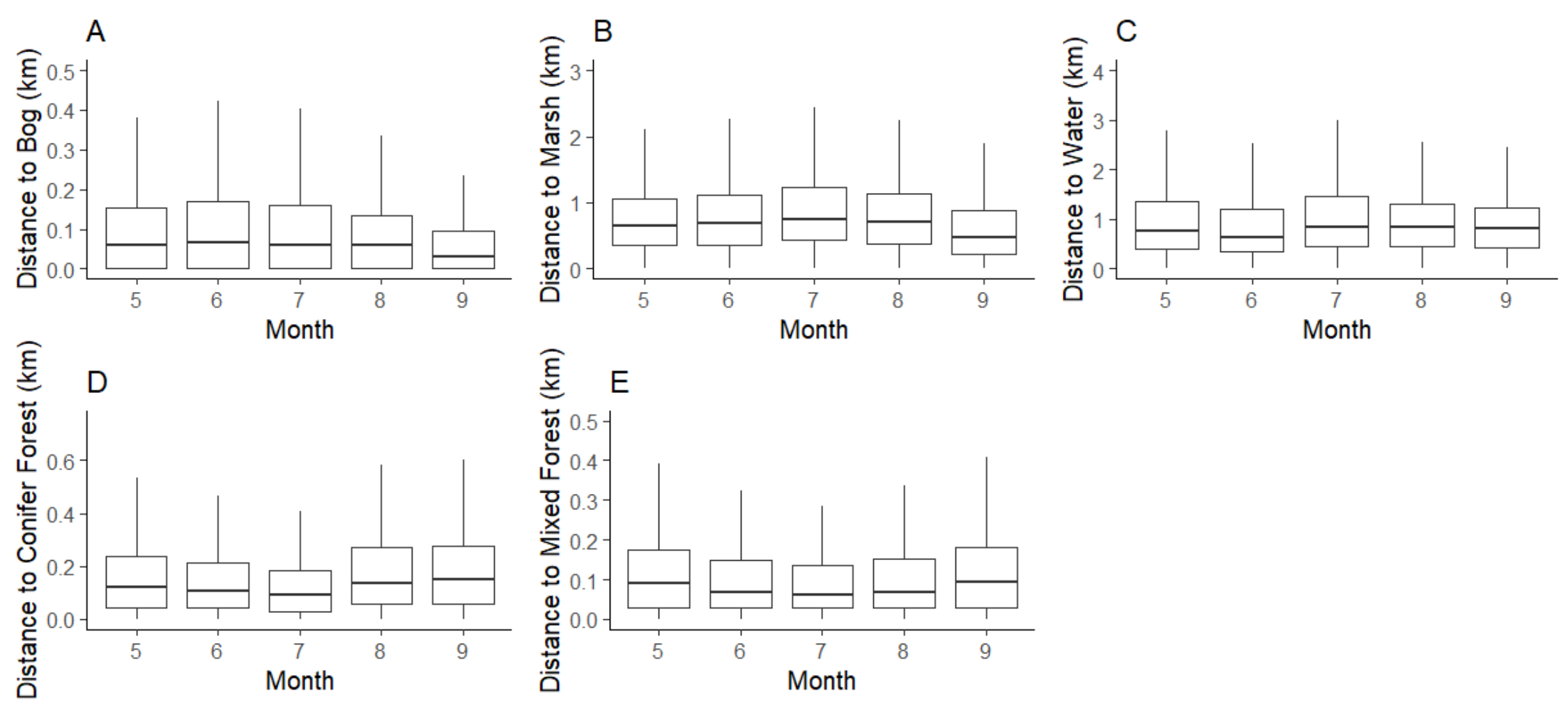
Fig. A4 Interaction plots showing relationships for significant interactions between temperature and relative selection strengths (RSS) of variables of interest (A: Step length and temperature, B: Shade and temperature, C: Distance to bog and temperature, D: Distance to mixed forest and temperature) at progressively longer intervals between GPS locations (1: 20-minute, 2: 1-hour, 3: 2-hour, and 4: 4hour). Patterns in the selection strength of interactions progressively weaken as the interval between GPS locations increases, in part explaining why other studies have not found consistent effects of temperature on moose movement.
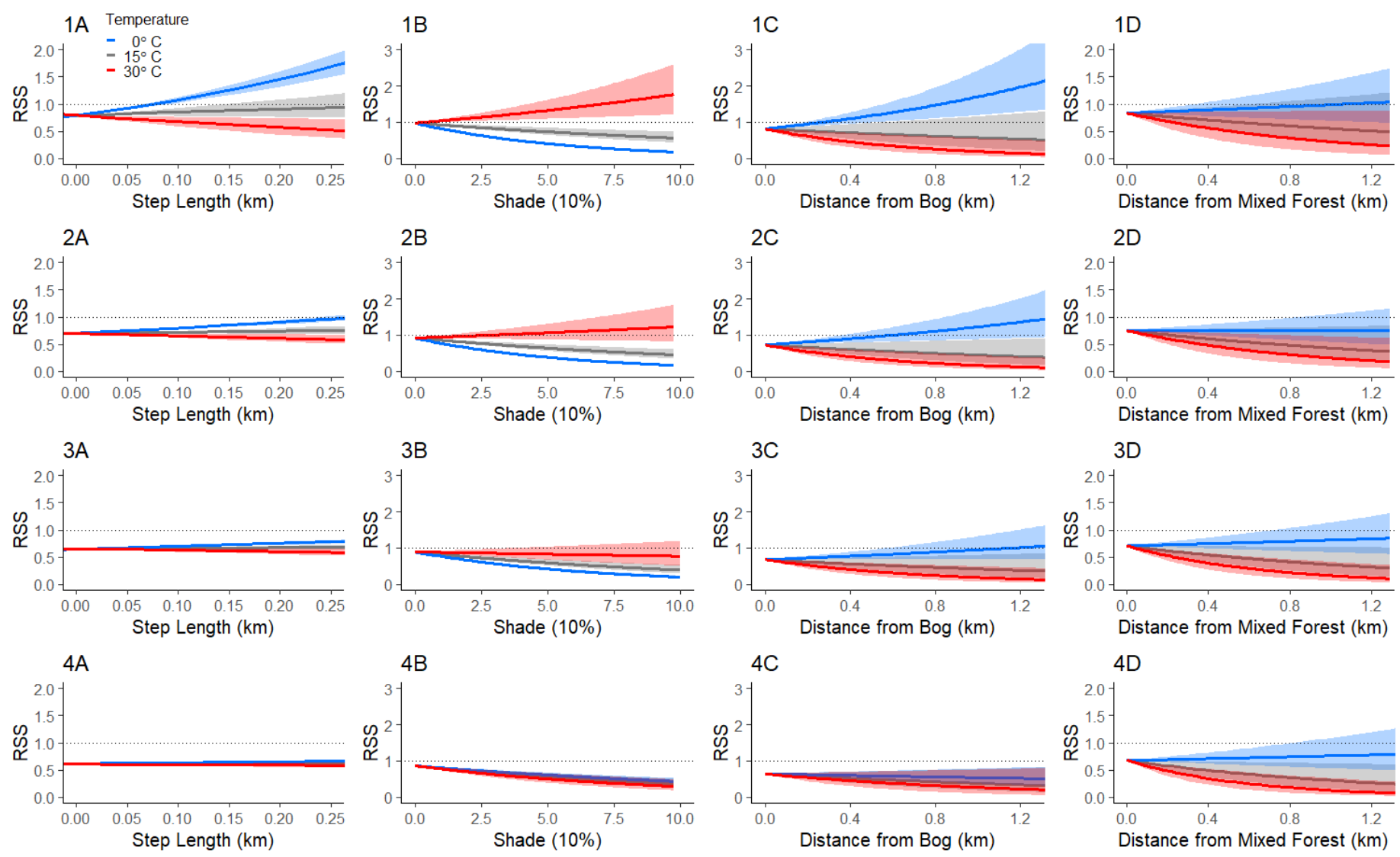